\title{
UNA LECTURA SEMIÓTICA DEL COURS EN EL AÑO DE SU CENTENARIO (SEGUNDA PARTE)
}

\author{
A SEMIOTIC READING OF THE COURS IN THE YEAR OF ITS \\ CENTENNIAL (PART TWO)
}

Mirko LAMPIS

Universidad Constantino el Filósofo de Nitra

mlampis@ukf.sk

Fecha de Recepción: 10-03-2018

Fecha de Aceptación: 17-05-2018

RESUMEN:

El objetivo de este artículo es el de estudiar y describir los fundamentos teóricos del Cours de linguistique générale, de F. de Saussure (1 $1^{\mathrm{a}}$ ed.: 1916). Más concretamente, estudiaremos aquí la noción de langue (su estatus y sus consecuencias explicativas) y el problema del cambio y de las dinámicas temporales del sistema estudiado (el problema de la diacronía).

Palabras Clave: Semiótica; Ferdinand de Saussure; Langue; Sincronía y diacronía.

\section{AbSTRACT:}

The goal of this paper is to study and describe the theoretic foundations of the Cours de linguistique générale, by F. de Saussure (1st ed.: 1916). More specifically, we will study here the notion of langue (its explanative status end consequences) and the problem of change and temporal dynamics of studied system (problem of diachrony).

Key Words: Semiotics; Ferdinand de Saussure; Langue; Synchrony and diachrony. 


\section{INTRODUCCIÓN}

Vamos a dar continuación, en estas páginas, a nuestra lectura semiótica del Curso de lingüística general de Ferdinand de Saussure, lectura que empezamos a articular y seguiremos articulando alrededor de los siguientes recorridos textuales:

— primer recorrido: hacia una ciencia del lenguaje;

- segundo recorrido: la semiología;

— tercer recorrido: del habla a la lengua;

— cuarto recorrido: el problema del tiempo;

— quinto recorrido: forma y sustancia, potencia y acto;

— sexto recorrido: el significado.

Ya analizamos los dos primeros recorridos en la primera parte de nuestro texto (Lampis, 2018), de modo que nos ocuparemos aquí del tercer recorrido (del habla a la lengua) y del cuarto (el problema del tiempo).

Lógicamente, siendo este artículo una "segunda parte", para su correcta introducción y comprensión sería menester tener en cuenta lo expuesto y sostenido en la primera; resumiremos pues, para mayor comodidad del lector, las principales conclusiones que ahí se formulan.

1) La organización del Curso, así como la de los materiales que sus editores emplearon para confeccionarlo, está íntimamente motivada por la necesidad de dar una fundamentación racional y rigurosa — es decir, un estatus científico incuestionable - a la disciplina lingüística; las elecciones teóricas y terminológicas que se derivan de tal necesidad influirán profundamente en la elaboración de la semiótica contemporánea ${ }^{1}$.

2) El objetivo de la lingüística científica es hallar y definir las leyes generales y las invariantes que gobiernan el funcionamiento y la historia de todas las lenguas. A fin de alcanzar dicho objetivo, considerando la extrema complejidad del lenguaje humano - y, asimismo, el estado de confusión que caracterizaba, en opinión de Saussure, los estudios lingüísticos de su tiempo-, se vuelve necesaria una definición más precisa y rigurosa de los límites de la disciplina, de su metodología y de su objeto de estudio.

3) Saussure lleva adelante una doble estrategia legitimadora. Por un lado, trata de establecer conexiones claras y precisas entre la lingüística y las demás disciplinas científicas, definiendo el lugar que le corresponde a la primera en el sistema de las ciencias. Por otro, trata de definir de forma rigurosa su objeto de estudio y su metodología. A la primera estrategia podemos reconducir la noción saussureana de semiología; a la segunda, la noción de lengua.

\footnotetext{
1 Acerca de las últimas tendencias en la semiótica de inspiración saussureana y en la crítica semiótica al pensamiento de Saussure, se puede consultar la revista digital Texto! Textes \& Cultures (http://www.revue-texto. net/index.php); véase, en particular, Rastier, 2005, y Boquet, 2005.
} 
4) Desde un punto de vista metodológico, la estrategia científica que Saussure lleva a cabo es aislante y reduccionista: tarea de la ciencia es la de simplificar una realidad fenoménica demasiado "caótica", abstrayendo y aislando un sistema limitado e invariante de leyes, relaciones y elementos y reduciendo a su funcionamiento la pluralidad de las manifestaciones observadas.

5) La lingüística no es, en opinión de Saussure, una ciencia fisiológica ni histórica, sino semiológica. La semiología es una ciencia psicológica, pues en todo caso atañe a las manifestaciones del espíritu humano, y más específicamente una ciencia sociológica, ya que se ocupa de tales manifestaciones en el transcurso del vivir social. Su objeto específico no son las realizaciones sígnicas contingentes, sino el sistema de oposiciones relevantes que las fundamenta y que se halla en la conciencia de los miembros de la colectividad.

6) La linguiística, a través de la noción de semiología, encuentra su "lugar natural" en la jerarquía de las ciencias humanas y se independiza de aquellas disciplinas que hasta entonces habían mantenido el monopolio de los estudios lingüísticos: la gramática, la filología y la gramática comparada. Se establece, además, siendo la lingüística la ciencia semiológica más avanzada y la lengua el más importante de los sistemas de signos, un nuevo y fértil terreno de aplicaciones, comparaciones y generalizaciones explicativas. Saussure cae aquí, sin embargo, en una flagrante petitio principii: la linguiística es sólo una rama especializada de la semiología, disciplina que todavía no existe y cuyo exponente más prestigioso sería... la propia lingüística; así, todos los principios semiológicos generales enunciados por Saussure son principios referidos a la lengua para los que se supone, sin más, una generalización semiológica, aunque sería su valor semiológico general lo que (también) debería determinar su legitimidad en tanto que principios científicos.

Llegamos así a los recorridos textuales que queremos desarrollar más detalladamente en las siguientes páginas y que giran alrededor de aquellas que son probablemente las más comentadas y discutidas dicotomías saussureanas: la oposición entre langue y parole y la oposición entre sincronía y diacronía. Ya en los breves resúmenes presentados aquí arriba el problema es patente, ya que la definición de un objeto de estudio estable y analizable de forma rigurosa implicaba la necesidad de dar cuenta, de algún modo, de las variaciones idiolectales y diacrónicas que afectan constantemente al "heteróclito" lenguaje humano. La langue es, precisamente, el sistema que los lingüistas deben abstraer y aislar del conjunto de los hechos del lenguaje, el principio ordenador al que intentar reducir — si no ontológica, sí explicativamente - todas las manifestaciones lingüísticas.

\section{TERCER RECORRIDO: DEL HABLA A LA LENGUA}

Así se define, en el Curso, la noción de lengua (langue):

i) la lengua no es más que una determinada parte del lenguaje, aunque esencial. Es a la vez un producto social de la facultad del lenguaje y un conjunto de convenciones nece- 
sarias adoptadas por el cuerpo social para permitir el ejercicio de esa facultad en los individuos (Saussure, 1973: 51).

ii) es una totalidad en sí y un principio de clasificación. En cuanto le damos el primer lugar entre los hechos del lenguaje, introducimos un orden natural en un conjunto que no se presta a ninguna otra clasificación (51).

iii) Es un tesoro depositado por la práctica del habla en los sujetos que pertenecen a una misma comunidad, un sistema gramatical virtualmente existente en cada cerebro, o, más exactamente, en los cerebros de un conjunto de individuos, pues la lengua no está completa en ninguno, no existe perfectamente más que en la masa (57).

iv) Es un objeto bien definido en el conjunto heteróclito de los hechos de lenguaje. Se la puede localizar en la porción determinada donde una imagen acústica viene a asociarse con un concepto. La lengua es la parte social del lenguaje, exterior al individuo, que por sí solo no puede ni crearla ni modificarla; no existe más que en virtud de una especie de contrato establecido entre los miembros de una comunidad. Por otra parte, el individuo tiene necesidad de un aprendizaje para conocer su funcionamiento; el niño la va asimilando poco a poco (58).

v) es un objeto que se puede estudiar separadamente [...] Mientras que el lenguaje es heterogéneo, la lengua así delimitada es de naturaleza homogénea: es un sistema de signos en el que sólo es esencial la unión del sentido y de las imágenes acústicas, y donde las dos partes del signo son igualmente psíquicas (58-59).

vi) es un objeto de naturaleza concreta [...]. Los signos lingüísticos no por ser esencialmente psíquicos son abstracciones: las asociaciones ratificadas por el consenso colectivo, y cuyo conjunto constituye la lengua, son realidades que tienen su asiento en el cerebro (59).

vii) La lengua es un sistema basado en la oposición psíquica de esas impresiones acústicas, lo mismo que un tapiz es una obra de arte producida por la oposición visual entre hilos de colores diversos; ahora bien, lo que importa para el análisis es el juego de esas oposiciones, no los procedimientos con que se han obtenido los colores (84).

viii) La lengua es para nosotros el lenguaje menos el habla. La lengua es el conjunto de los hábitos lingüísticos que permiten a un sujeto comprender y hacerse comprender [...] Pero esta definición deja todavía a la lengua fuera de su realidad social, y hace de ella una cosa irreal, ya que no abarca más que uno de los aspectos de la realidad, el aspecto individual; hace falta una masa parlante para que haya una lengua. Contra toda apariencia, en momento alguno existe la lengua fuera del hecho social, porque es un fenómeno semiológico. Su naturaleza social es uno de sus caracteres internos (143-144).

ix) la lengua es un sistema de puros valores que nada determina fuera del estado momentáneo de sus términos (148).

x) La lengua es un mecanismo que sigue funcionando a pesar de los deterioros que se le causan (157).

xi) La lengua es un sistema en el que todas las partes pueden y deben considerarse en su solidaridad sincrónica (157).

xii) la lengua es un sistema en donde todos los términos son solidarios y donde el valor de cada uno no resulta más que de la presencia simultánea de los otros (195).

xiii) la lengua es una forma y no una sustancia (206).

La lengua es, en suma, un sistema ordenado y estable de elementos interdependientes y de relaciones diferenciales que fundamentan el uso lingüístico de una sociedad dada en un momento dado de su historia y es por este motivo, cabe concluir, que una lingüística cientí- 
fica resulta posible sólo si nos colocamos "desde el primer momento en el terreno de la lengua" y la tomamos "como norma de todas las otras manifestaciones del lenguaje" (Saussure, 1973: 51).

Ahora bien, al considerar con atención las definiciones de Saussure, se diría que en su sistema nocional la langue adquiere tres diferentes dimensiones explicativas (no necesariamente congruentes entre sí):

1) la lengua es un repertorio integrado de elementos: una totalidad en sí (ii); un tesoro (iii); un sistema gramatical virtualmente existente en cada cerebro (iii); un sistema de signos (v); un objeto de naturaleza concreta (vi); un sistema en donde todos los términos son solidarios (xii);

2) la lengua es un sistema de hábitos colectivos establecidos de forma convencional: un producto social (i); un conjunto de convenciones (i); la parte social del lenguaje (iv); un sistema que no existe más que en virtud de una especie de contrato establecido entre los miembros de una comunidad (iv); el conjunto de las asociaciones ratificadas por el consenso colectivo (vi); un conjunto de hábitos lingüísticos que no existe fuera del hecho social (viii);

3) la lengua es un marco normativo/explicativo: un principio de clasificación (ii); un orden natural que introducimos en un conjunto que no se presta a ninguna otra clasificación (ii); un objeto que se puede estudiar separadamente y que, así delimitado, es de naturaleza homogénea (v); un sistema de puros valores (ix); una forma (xiii).

Ya de entrada, pues, la langue se nos presenta como una noción sustancialmente ambigua, polifacética, y de hecho los comentaristas, exégetas y críticos del Curso, por lo común, se han centrado en, o han destacado sobre las demás, una sola de las dimensiones señaladas (De Mauro, por ejemplo, en sus comentarios al libro ha insistido particularmente en la tercera $)^{2}$.

Antes de proseguir, cabe recordar que la operación de distinguir entre una langue y una parole es anterior, tal como señala Coseriu (1992), a la formulación de Saussure ${ }^{3}$. Y cabe recordar, asimismo, que la distinción volverá una y otra vez en la lingüística post-saussu-

${ }^{2}$ Estas tres dimensiones de la langue, claro está, tienen sus equivalentes en el terreno de la parole, noción que vendría a indicar: 1) un conjunto parcial y contingente de selecciones y actualizaciones de los elementos de la langue; 2) un sistema de operaciones individuales; 3 ) una "masa bruta" de producciones lingüísticas sobre las que intervienen condicionantes de diferente naturaleza (físicos, fisiológicos, psicológicos, sociales, históricos, etc.).

${ }^{3}$ Es posible reconducir la dicotomía langue-parole, antes que a Saussure, a: i) las nomenclaturas espontáneas de diferentes lenguas nacionales (incluido el español; cabe notar, al respecto, que el doblete lengua-habla, en la traducción de A. Alonso, tiene su cabal justificación diccionarial: en la edición de 1939 del diccionario académico, encontramos la voz "lengua" definida como "Conjunto de palabras y modos de hablar de un pueblo y una nación" y la voz "habla" como "Faculta de hablar II 2. Acción de hablar"; es esta segunda acepción, junto con la naturaleza más abstracta de la definición de "lengua", lo que justifica la elección terminológica de Alonso); ii) el sistema clásico del trivium, con la distinción entre gramática, por un lado, y retórica y dialéctica, por otro; iii) algunas observaciones de Hegel, de W. von Humboldt, del lingüista y latinista danés J. M. Madvig y, en modo más elaborado y explícito, del lingüista alemán G. von der Gabelentz, ya contemporáneo de Saussure (Coseriu, 1992: 15-35). 
reana: baste pensar en los dobletes "esquema-uso" (Hjelmslev), "competencia-actuación" (Chomsky), "estructura profunda-estructura superficial" (Greimas) o en la moderna distinción entre norma y uso de la lengua. En todos estos casos, sin embargo, la justificación de la existencia de las regularidades (esquemas, estructuras, normas) subyacentes a las actuaciones y los usos lingüísticos — aunque pueda depender de diferentes órdenes de actividades y procesos: socio-consensuales (Saussure), lógico-formales (Hjelmslev y Greimas) y aun biológicos $\left(\mathrm{Chomsky}^{4}\right)$ - responde a una misma exigencia descriptivo-analítica y esta exigencia, a su vez, se deriva de una manera determinada de entender e interpretar la labor científica. Creo que el biólogo francés Jaques Monod lo ha resumido de forma muy clara y sucinta:

el descubrimiento de las invariantes representa la estrategia fundamental adoptada por la ciencia para analizar los fenómenos. Cada ley física, como por lo demás todo desarrollo matemático, define una relación de invariancia; las proposiciones más fundamentales formuladas por la ciencia son postulados universales de conservación. Eligiendo un ejemplo cualquiera, es fácil ver cómo el análisis de cualquier fenómeno resulta imposible en términos que no sean los de las invariantes que él mismo conserva (Monod, 2010: 94; la traducción es mía).

Si no se admitieran y registraran tales invariantes, entonces tampoco habría ciencia, así en física como en biología o en cualquier otro ámbito investigativo. Saussure, que se daba bien cuenta de ello, identificó el sistema de las invariantes lingüísticas con la langue, la estructura de las relaciones y oposiciones (psíquicas) que se dan entre los signos lingüísticos (y entre sus significantes y significados) en un estado determinado del lenguaje.

Ahora bien, la operación de individuar y describir un sistema de invariantes, como también señala Lepschy (1979: 346), es una operación de tipo abstractivo y conduce a la elección y al aislamiento de un conjunto de fenómenos regulares subyacentes a las concretas

\footnotetext{
${ }^{4}$ En efecto, en el caso de la lingüística generativo-transformacional de Chomsky, lo que justifica y garantiza la cientificidad de la práctica analítica no son las regularidades comunicativas consensual o lógicamente establecidas, sino algo mucho más radical: la gramática universal está determinada genéticamente y constituye por lo tanto un órgano natural que se desarrolla independientemente de las condiciones de contorno. Según Chomsky, los usos lingüísticos están determinados por las propiedades computacionales, intrínsecas y generales, de la mente/cerebro: existe una gramática universal, biológicamente determinada, y el aprendizaje de una lengua concreta consiste sólo en una "calibración” y "selección” de los parámetros predeterminados por la dotación biológica innata. La postura chomskiana resulta, sin embargo, sustancialmente ambigua. Por un lado, se reconoce la importancia del ambiente, puesto que este "debe proporcionar una estimulación lo suficientemente rica a fin de que los procesos genéticamente determinados se desarrollen de la forma en que están programados a desarrollarse" (Chomsky, 1991: 156); por otro, se recuerda que el ambiente es demasiado pobre e indeterminado como para proporcionar al niño un sistema tan rico y creativo como el del lenguaje y que el desarrollo de este sistema, más bien, es análogo al de la pubertad: no se trata de procesos que uno aprende a llevar a cabo porque los realizan los demás; uno sólo está programado para llevarlos a cabo (Chomsky, 1991: 157).

${ }^{5}$ De forma consecuente con su postura teórica general, Monod afirma que ni las mutaciones genéticas ni los procesos evolutivos constituyen propiedades definitorias de los seres vivos, puesto que dependen de imperfecciones y accidentes debidos a un malfuncionamiento de los mecanismos conservadores en el proceso de invariancia. Hoy en día, sin embargo, el descubrimiento y el análisis de las invariantes ya no es, tal como sostenía Monod, "la estrategia fundamental de la ciencia" y el estudio de la variancia, la singularidad y la deriva ha venido cobrando cada vez más protagonismo.
} 
manifestaciones estudiadas. La abstracción es ciertamente una práctica legítima y común, en el mundo de la ciencia ${ }^{6}$, pero considérese, entonces, aquellas disciplinas lingüísticas que programáticamente se enfrentan a la heterogeneidad y al dinamismo de la parole, el dominio de las concretas realizaciones (actuaciones, usos, textos) de los hablantes: disciplinas como la historia de la lengua (o lingüística diacrónica), la dialectología (o linguiística geográfica) y la sociolingüística; tienen su importancia, ni Saussure lo niega ni nadie puede dudarlo; es más, el propio Saussure dedica una parte considerable de sus cursos al tratamiento de cuestiones diacrónicas y geográficas; pero resulta claro, a partir del planteamiento saussureano, que las únicas posibilidades de instituir tales disciplinas como otras tantas prácticas científicas pasan por nuestra capacidad de coordinar sus métodos y sus resultados con los de la lingüística de la langue. Repitámoslo: para que la lingüística alcance un estatus científico incuestionable, "hay que colocarse desde el primer momento en el terreno de la lengua y tomarla como norma de todas las otras manifestaciones del lenguaje" (Saussure, 1973: 51).

No se olvide, además, que la noción de langue, como forma pura de nexos y oposiciones estructurantes, guarda estrecha relación con el llamado principio de inmanencia, principio que con Hjelmslev y Greimas, y también, aunque de forma distinta, con Chomsky, se convertirá en una de las piedras angulares — para muchos autores, la piedra angular- de las metodologías lingüísticas y semióticas: sólo la operación de reducir el lenguaje y sus realizaciones a una estructura de relaciones formales ("profundas") totalmente independientes de consideraciones de orden material o contextual puede garantizar la consistencia y el valor de la práctica científica?

${ }^{6}$ De acuerdo con las recomendaciones de De Mauro, y respetando también la preocupación de Saussure y sus editores al señalar que la langue, no menos que la parole, "es un objeto de naturaleza concreta" y que los signos lingüísticos "no por ser esencialmente psíquicos son abstracciones" (Saussure, 1973: 59), recuerda Lepschy que hay que entender la oposición abstracto-concreto "en el sentido de la metodología de la ciencia moderna, donde la abstracción pertenece necesariamente a la hipótesis científica, y no presenta implicaciones negativas o limitativas, así como en cambio sucede con frecuencia en el clima positivista de finales del siglo XIX y aún en el CLG" (Lepschy, 1979: 346; la traducción es mía). Valga como prueba del uso negativo de la noción de "abstracto" la crítica de Meillet citada por A. Alonso (1945: 28): "Ya Antoine Meillet, el más ilustre de los secuaces de Saussure, declaró al reseñar el Cours (Bull. Soc. Ling. París, 1916, XX, pág. 35) que la doctrina saussureana, ceñida exclusivamente al aspecto sistemático de la lengua, era demasiado abstracta, sin la necesaria atención a la realidad humana e histórica en que la lengua nada y vive". Por otro lado, en cuanto a la abstracción como operación científica, merece la pena leer la siguiente opinión de Chomsky: "Los lingüistas siempre han operado, y justamente, una idealización: démonos, dicen, la idea de una comunidad lingüística homogénea [...] me parece el solo sistema de proceder racionalmente. Estudiamos los sistemas ideales, y luego podemos interrogarnos acerca de la manera en la que, en los individuos reales, estos sistemas ideales entran en interacción. [...] Así pues, hay que abstraer un objeto, hay que eliminar los factores no pertinentes" (en Lepschy, 1979: 348; la traducción es mía). El problema de este planteamiento, sin embargo, es que a menudo se olvida el riesgo, siempre presente, de que la "abstracción buena, inherente al proceso de explicación científica", se acerque peligrosamente, como apunta Lepschy (ibíd.), a la "abstracción mala, la que en ocasiones debe prescindir de ciertos datos no porque no sean pertinentes, sino porque son refractarios”. Se presenta aquí con fuerza, además, la difícil cuestión de la pertinencia: ¿quién, cómo y por qué decide lo que es y no es pertinente?

7 Resulta sintomático el siguiente juicio de Greimas, citado por Coquet (2008: 27): gracias al principio de inmanencia, "tal vez por primera vez, el término 'científico', referido al campo de las ciencias humanas, pierde su uso metafórico". 
En cuanto a la relación que se da entre langue y parole, se puede sin duda aceptar, con Barthes (1990: 23), que "cada uno de estos términos extrae evidentemente su definición plena sólo del proceso dialéctico que los une; no hay lengua sin habla y no hay habla fuera de la lengua". Por ende, si existe en Saussure una preeminencia de la langue, es una preminencia esencialmente metodológica, mientras que el lingüista suizo no niega ni oculta la prioridad diacrónica y evolutiva del habla:

la lengua es necesaria para que el habla sea inteligible y produzca todos sus efectos; pero el habla es necesaria para que la lengua se establezca; históricamente, el hecho de habla precede siempre. ¿Cómo se le ocurriría a nadie asociar una idea con una imagen verbal, si no se empezara por sorprender tal asociación en un acto de habla? Por otra parte, oyendo a los otros es como cada uno aprende su lengua materna, que no llega a depositarse en nuestro cerebro más que al cabo de innumerables experiencias. Por último, el habla es la que hace evolucionar a la lengua: las impresiones recibidas oyendo a los demás son las que modifican nuestros hábitos lingüísticos. Hay, pues, interdependencia de lengua y habla: aquélla es a la vez el instrumento y el producto de ésta (Saussure, 1973: 64-65).

O en este otro texto, un informe acerca de la posibilidad de abrir una catedra de estilística en su universidad, en el que escribe Saussure:

Lo que ocurre es que la lingüística, me atrevo a decirlo, es muy amplia. Particularmente, comporta dos partes: una que se halla más cerca de la lengua, acervo pasivo, y otra que se halla más cerca del habla, fuerza activa y auténtico origen de los fenómenos que se perciben a continuación en la otra mitad del lenguaje (Saussure, 2004: 244).

A este reconocimiento de la estrecha relación entre lengua y habla hay que añadir también la admisión ocasional de que la langue, tanto en su estructura interna como en sus relaciones con la parole, no siempre parece amoldarse a los modelos descriptivos propuestos. Existen, por ejemplo, límites en la coherencia sincrónica del sistema: "No hay momento en que una lengua posea un sistema perfectamente fijo de unidades" (Saussure, 1973: 274); y se presenta, asimismo, el problema de la naturaleza "híbrida" de las estructuras sintácticas: "hay que reconocer que en el dominio del sintagma no hay límite señalado entre el hecho de lengua, testimonio del uso colectivo, y el hecho del habla, que depende de la libertad individual" (Saussure, 1973: 211).

Saussure insiste una y otra vez en que todos los cambios que afectan al sistema de la langue tienen su origen en el dominio de la parole:

— todo cuanto es diacrónico en la lengua solamente lo es por el habla. En el habla es donde se halla el germen de todos los cambios: cada uno empieza por ser práctica exclusiva de ciertos números de individuos antes de entrar en el uso (Saussure, 1973: 172).

- Nada entra en la lengua sin haber sido ensayado en el habla; todos los fenómenos evolutivos tienen su raíz en la esfera del individuo (271).

- Mientras los hechos pertenezcan al habla, no son más que maneras especiales y completamente ocasionales de utilizar el sistema establecido. Sólo en el momento 
en que una innovación, repetida con frecuencia, se graba en la memoria y entra en el sistema, tiene el efecto de trastornar el equilibrio de los valores, y con ello se encuentra la lengua ipso facto y espontáneamente cambiada (235, nota de Bally y Sechehaye).

Las innovaciones, pues, aparecen en el uso individual y sólo gracias a las dinámicas propias de la comunicación social pueden ser "registradas", por así decirlo, en el uso social, convirtiéndose en una convención comúnmente aceptada, enseñada y aprendida, siendo así cómo un "hecho" de la parole se estabiliza y se convierte en una "regularidad" de la langue y cómo las "regularidades" de la langue se afirman y difunden:

La propagación de los hechos de la lengua está sujeta a las mismas leyes que cualquier otra costumbre, la moda por ejemplo. En toda masa humana hay dos fuerzas que actúan sin cesar simultáneamente y en sentidos contrarios: de un lado el espíritu particularista, el "espíritu de campanario"; del otro, la fuerza del intercambio que crea las comunicaciones entre los hombres (Saussure, 1973: 327).

En este sentido, el pensamiento de Saussure se enlaza con una tradición y un sentido común que se remontan a épocas pretéritas: la variedad del lenguaje, al igual que la variedad de todas las costumbres humanas, se debe al dinamismo propio de nuestra especie y a la idiosincrasia (y la libertad) de cada individuo. Nótese que se trata de una opinión que ya expresó cabalmente Dante Alighieri a comienzos del siglo XIV: el hombre es "instabilissimum atque variabilissimum animal", un animal cuyos hábitos y costumbres varían "per locorum temporumque distantias", así que tampoco "nostra loquela [...] nec durabilis nec continua esse potest" (Dante Alighieri, De vulgari eloquentia, Libro 1, IX, 6). Cabe decir que no parece fácil, en el ámbito de esta tradición, encarar el problema de los límites de la langue, es decir, el problema del limes o umbral — temporal, geográfico, social, estadístico- más allá del cual un fenómeno (singular) de la parole se convierte en un fenómeno (general) de la langue. Podría ser este un falso problema, desde luego, si se considera que la lingüística sólo se enfrenta a estados sincrónicos ya constituidos, institucionalizados y listos para el análisis; pero se vuelve relevante si la atención se desplaza hacia la mutabilidad y heterogeneidad — cuando no conflictividad — detectables en todo sistema lingüístico.

Hay que entender, desde este punto de vista, que la insistencia en la inestabilidad y el dinamismo de los hechos de parole y en las relaciones que vinculan tales procesos con la conformación del sistema de la langue no hace más que remarcar, en la teoría saussureana, la naturaleza sincrónica y estable de dicho sistema y la exigencia de basar en él el estudio del lenguaje, puesto que sólo la langue puede proporcionar aquellas coordenadas invariantes que regulan el uso social del lenguaje y a la vez consienten una aproximación analítica rigurosa. Y no puede sorprender, por lo tanto, que la reacción a la lingüística saussureana se concretara sobre todo en la exigencia de volver a la parole (a la comunicación, al discurso, al habla) como campo legítimo y aun prioritario de investigación, desde autores ya clásicos como Jakobson, Benveniste y Coseriu hasta llegar a las últimas tendencias en lingüística pragmática y en lingüística ecológica (véase Bastardas Boada, 2016). 
A partir de premisas neo-idealistas que no podemos ya compartir, Amado Alonso, en la introducción a su traducción del Cours, trae a colación a Humboldt y su frase-bandera: "el lenguaje es esencialmente enérgeia, no érgon", actividad, no producto, para luego concluir que la enérgeia se corresponde, en la terminología de Saussure, a la parole, y no a la langue (Alonso, 1945: 27) ${ }^{8}$. En realidad, sabemos ahora que el lenguaje es ambas cosas, actividad $y$ producto, proceso y sistema, y que los socio-, dia- e ideo-lectos, con sus usos y sus normas, instauran complejas relaciones generativas y de interdependencia en contextos comunicativos cambiantes y estratificados. La abstracción sigue siendo, desde este punto de vista, un instrumento analítico legítimo, acaso necesario, pero jamás, en un sentido u otro, debería servir para crear entidades autónomas.

\section{CUARTO RECORRIDO: EL PROBLEMA DEL TIEMPO}

Es conocida la crítica que los autores del Círculo lingüístico de Praga, en sus Tesis de 1929, dirigieron a la "escuela de Ginebra" y a su tratamiento de la oposición entre sincronía y diacronía:

No se pueden poner barreras infranqueables entre los métodos sincrónico y diacrónico, tal como hace la escuela de Ginebra. Si, desde el horizonte de la lingüística sincrónica, enfocamos los elementos del sistema lingüístico desde el punto de vista de sus funciones, no podremos evaluar las alteraciones sufridas por la lengua sin dar cuenta del sistema que por ellas está afectado. No sería, pues, lógico suponer que los cambios lingüísticos son alteraciones destructivas casuales y heterogéneas en la perspectiva del sistema. Los cambios lingüísticos apuntan frecuentemente al sistema, su estabilización, su reconstrucción, etc. Por consiguiente, el estudio diacrónico no sólo no excluye las nociones de sistema y función, sino que, por el contrario, es incompleto si no se tienen en cuenta.

Por otro lado, la descripción sincrónica no puede excluir absolutamente la noción de evolución, porque incluso en un sector considerado sincrónicamente existe la conciencia del estadio en vías de desaparición, del estadio presente y del que se está formando; los elementos estilísticos concebidos como arcaísmos, y en segundo lugar, la distinción entre formas productivas y no productivas, son hechos diacrónicos que no se pueden eliminar de la lingüística sincrónica (Círculo lingüístico de Praga, 1970: 16-17).

Esta crítica estaba sustancialmente motivada por algunas de las afirmaciones más controvertidas del Curso, relativas a la necesidad de una separación metodológica radical entre los estudios sincrónicos, que ponen en relación hechos simultáneos, pertenecientes e interactuantes en el mismo sistema, y los estudios diacrónicos, que ponen de manifiesto la sustitución en el tiempo de formas específicas por otras formas específicas:

\footnotetext{
${ }^{8}$ Coseriu (1992: 25) defiende que no es legítimo identificar la dicotomía saussureana de langue-parole con la humboldtiana de érgon-enérgeia, puesto que el erudito alemán definió como enérgeia no sólo "el hablar de cada vez", sino también, aunque en menor medida, "una lengua" y "la lengua como totalidad del hablar", nociones estas ya cercanas a la langue de Saussure. Me parece, sin embargo, que la descripción saussureana de la langue sí acerca, y mucho, esta noción a la de érgon.
} 
i) Lo primero que sorprende cuando se estudian los hechos de lengua es que para el sujeto hablante su sucesión en el tiempo es inexistente: el hablante está ante un estado. Así el lingüista que quiere comprender ese estado tiene que hacer tabla rasa de todo lo que lo ha producido y desentenderse de la diacronía. Nunca podrá entrar en la conciencia de los sujetos hablantes más que suprimiendo el pasado. La intervención de la historia sólo puede falsear su juicio. Sería absurdo dibujar un panorama de los Alpes tomándolo simultáneamente desde varias cumbres del Jura; un panorama tiene que trazarse desde un solo punto. Lo mismo para la lengua: no se puede ni describirla ni fijarle normas para el uso más que colocándose el lingüista en un estado determinado (Saussure, 1973: 149).

ii) La oposición entre los dos puntos de vista — sincrónico y diacrónico-es absoluta y no tolera componendas (151).

iii) Querer reunir en la misma disciplina hechos tan dispares sería, pues, una empresa quimérica. En la perspectiva diacrónica nos ocupamos de fenómenos que no tienen relación alguna con los sistemas, a pesar de que los condicionan (155).

iv) La lengua es un mecanismo que continúa funcionando a pesar de los deterioros que se le causan.

Esto confirma los principios ya formulados y que resumimos así:

La lengua es un sistema en el que todas las partes pueden y deben considerarse en su solidaridad sincrónica.

Como las alteraciones jamás se hacen sobre el bloque del sistema, sino sobre uno u otro de sus elementos, no se pueden estudiar más que fuera del sistema. Sin duda, cada alteración tiene su repercusión en el sistema; pero el hecho inicial ha afectado a un punto solamente; no hay relación íntima alguna con las consecuencias que se puedan derivar para el conjunto. Esta diferencia de naturaleza entre términos sucesivos y términos coexistentes, entre hechos parciales y hechos referentes al sistema, impide hacer de unos y otros la materia de una sola ciencia (157).

v) La oposición entre lo diacrónico y lo sincrónico salta a la vista en todos los puntos (161).

vi) el "fenómeno" sincrónico nada tiene en común con el diacrónico [...]; el uno es una relación entre elementos simultáneos, el otro la sustitución de un elemento por otro en el tiempo, un suceso (162).

vii) Así es como la lingüística se encuentra aquí ante su segunda bifurcación. Ha sido primero necesario elegir entre la lengua y el habla [...]; ahora estamos en la encrucijada de rutas que llevan la una a la diacronia, la otra a la sincronia (172).

viii) La lingüística sincrónica se ocupará de las relaciones lógicas y psicológicas que unen términos coexistentes y que forman sistema, tal como aparecen a la conciencia colectiva.

La lingüística diacrónica estudiará por el contrario las relaciones que unen términos sucesivos no percibidos por una misma conciencia colectiva, y que se reemplazan unos a otros sin formar sistema entre sí (174).

ix) La gramática estudia la lengua como sistema de medios de expresión; quien dice gramatical dice sincrónico y significativo, y como ningún sistema está a caballo sobre varias épocas a la vez, no hay para nosotros una "gramática histórica”; la que así se llama no es en realidad más que la lingüística diacrónica (223).

x) En materia de análisis sólo podremos, pues, establecer un método y formular definiciones después de habernos situado en el plano sincrónico (295). 
También Amado Alonso (1945: 13) se refiere a esta, como él la define, "sorprendente concepción de las relaciones — de la falta de relación directa — entre la diacronia y la sincronia", concepción que en su opinión "deslumbró a algunos, desconcertó a otros y por fin desató la oposición más viva y general". A pesar de la actitud evidentemente censora de Alonso, comprensible a la luz de sus concepciones neo-idealistas acerca del papel que en el devenir de la lengua desempeña el "espíritu", su resumen de la estrategia explicativa llevada a cabo por Saussure y los editores del Curso me parece sustancialmente correcto:

La ordenación resultante es ésta: el estudio sincrónico del sistema tiene la primacía; es más, es el único estrictamente lingüístico, a) porque el habla, como individual es asistemática, y como ejecutora de la lengua le es ajena, b) porque aun la lingüística diacrónica es lingüística a medias, ya que el objeto legítimo es la lengua como sistema, y los cambios (objeto de la lingüística diacrónica) no se producen para Saussure directamente en el sistema, sino en sus elementos aislados, que, de rebote, pueden traer al sistema consecuencias fortuitas (Alonso, 1945: 22).

El juicio de Saussure sobre la lingüística diacrónica no es tan negativo como quiere dar a entender Alonso —o por lo menos lo es únicamente con respecto a la lingüística diacrónica tal y como se había practicado hasta finales del siglo XIX-, pero sí es cierto que, en opinión de Saussure, toda posibilidad de sistematización rigurosa de la lingüística pasa, in primis, por el reconocimiento de la necesidad de separar convenientemente el estudio del sistema de la lengua del estudio de la evolución del lenguaje.

Ahora bien, Tullio De Mauro, de forma consecuente con su defensa "a ultranza" de la historicidad de la lingüística saussureana, sobre la que volveremos más adelante, comenta en su aparato de notas dos de los diez pasajes del Curso que he seleccionado y citado más arriba. Sobre todo el 'ii', en la extensa nota número 176 (De Mauro, 1967b: 425-429). Aquí, De Mauro, tras calificar el pasaje como "otra crux de la exégesis y de la prosecución de las tesis saussureanas", insiste, justamente, en la naturaleza metodológica, y no ontológica, de la oposición sincronía-diacronía. No por nada en 'ii' se habla, explícitamente, de dos puntos de vista. Sin embargo,

Casi todos los que han intervenido en la discusión se han decantado por la "superación" de la "separación" de sincronía y diacronía. Se ha creído comúnmente que la distinción se pone, per S., in re: el objeto "lengua” tiene una sincronía y una diacronía [...] A la distinción así entendida se han movido objeciones de orden historicista y de orden estructuralista (De Mauro, 1967b: 425; la traducción es mía).

De Mauro, por ende, achaca a una tergiversación la mayoría de las críticas dirigidas a Saussure, quien en realidad se refiere a una diferencia de puntos de vista sobre el objet de la lingüística y recuerda, muy a menudo, el estado de continua evolución y re-sistematización en que se halla dicho objet. Saussure, en otros términos, es perfectamente consciente tanto "del dinamismo de las situaciones lingüísticas en una época dada" como "de las consecuen-

\footnotetext{
9 Así emplea las voces "sincronía” y “diacronía” Amado Alonso: llanas y con diptongo final.
} 
cias que todo cambio tiene en el plano del sistema" (De Mauro, 1967b: 428). En cuanto a la diferencia entre el punto de vista sincrónico y el diacrónico, comenta De Mauro:

Desde el punto de vista del método de investigación y exposición no se ve cómo se podría negar la duplicidad de la perspectiva sincrónica y de la perspectiva diacrónica: ¿acaso se quiere sostener que el valor de una entidad lingüística depende del valor que esta tuvo en una fase lingüística anterior? [...] En realidad, la lingüística no puede prescindir de la dúplice perspectiva sin con ello negar, por un lado, que el valor de una entidad depende del juego sincrónico del que esta es parte y sin caer, por otro lado, en una visión o animista o falsamente determinista de los cambios lingüísticos. Las dos perspectivas metodológicas, rigurosa consecuencia de la noción de arbitrariedad del signo [...], son el instrumento indispensable de una visión histórica y positiva de la realidad lingüística (De Mauro, 1967b: 428-429; la traducción es mía).

De Mauro, sin embargo, parece aquí olvidar u obviar la constatación, en sí trivial, de que defender la conveniencia (y aun la necesidad) de separar el estudio sincrónico de una lengua de su estudio diacrónico es operación muy distinta a la de defender, tal como hace Saussure en los diez pasajes citados, que en los estudios sincrónicos no se admiten ni deben admitirse consideraciones de orden diacrónico, y viceversa ${ }^{10}$. Me parece que es a esta inadmisibilidad metodológica que se refieren, polémicamente, los estructuralistas del Círculo de Praga (motivados, sin duda, por su concepción teleológica del lenguaje humano), Amado Alonso (a partir del neo-idealismo) u otros lingüistas que, como Coseriu (1992: 154-160) o los propios praguenses, insisten en la existencia de un específico saber diacrónico en los hablantes en todo estado sincrónico de una lengua; tales autores, en otros términos, no critican a Saussure por sostener que la langue es un sistema invariable en el tiempo, sino por defender — con muy pocas excepciones y oscilaciones - que los lingüistas, a fin de salvaguardar el rigor y la consistencia del análisis al estudiar y describir el sistema, deben prescindir de consideraciones de orden diacrónico, como si aquel fuera un "panorama" fijo en un estado determinado.

10 Naturalmente, la actitud de Saussure es mucho más laxa con respecto a la posibilidad de aplicar consideraciones de orden sincrónico al estudio de los procesos diacrónicos. Por ejemplo: al considerar los límites de los procesos de creación analógica, se escribe en el Curso que "la conservación de una forma puede deberse a dos causas exactamente opuestas: el aislamiento completo [como en el caso de los topónimos] o el estrecho enmarcamiento en un sistema que, quedando intacto en sus partes esenciales, viene constantemente en su ayuda" (Saussure, 1973: 277). De aquí la posibilidad ulterior de "reducir" los procesos diacrónicos a fenómenos de orden sincrónico, o estructural, como en la siguiente cita de Émile Benveniste: "La novedad del punto de vista saussuriano [...] fue adquirir conciencia de que el lenguaje en sí mismo no incluye ninguna dimensión histórica, que es sincronía y estructura, y que no funciona sino en virtud de su naturaleza simbólica. No es tanto la consideración histórica la que es por ello condenada, sino cierta manera de "atomizar" la lengua y mecanizar la historia. El tiempo no es el factor de la evolución; es nada más el marco. La razón del cambio que afecta a tal o cual elemento de la lengua está por una parte en la naturaleza de los elementos que la componen en un momento dado, por otra en las relaciones de estructura que hay entre dichos elementos. [...] La diacronía queda entonces restablecida en su legitimidad, en tanto que sucesión de sincronías. Esto pone ya de relieve la importancia primordial de la noción de sistemas y de la solidaridad restaurada entre todos los elementos de una lengua" (Benveniste, 1997: 7). 
Resulta interesante, desde este punto de vista, un comento que De Mauro, en su nota 183, dedica al pasaje del Curso que aquí hemos recogido como 'iv' (véase supra). El lingüista italiano señala que en este texto la oración "[las alteraciones] no se pueden estudiar más que fuera del sistema" es, probablemente, una interpolación de los editores; y añade:

las alteraciones son ciertamente externas al sistema, no determinadas por él ni causal ni teleológicamente, pero, puesto que cada una de ellas tiene "su repercusión en el sistema", parece necesario concluir que es al menos posible estudiar las alteraciones en relación al sistema (De Mauro, 1967b: 429; la traducción es mía).

Y es posible, de hecho. Es incluso necesario. Pero esta operación, que implicaría aplicar a la langue consideraciones de orden diacrónico, es precisamente lo que defienden los estructuralistas de Praga y Saussure pone metodológicamente en entredicho ${ }^{11}$.

Hay que reconocer el gran mérito de De Mauro al subrayar que la arbitrariedad del signo - en opinión de Saussure, no se olvide, el principio semiológico fundamental— es la primera y más salda garantía de la historicidad de todo sistema semiológico, lengua incluida $^{12}$. Ni Saussure, por otra parte, niega la dimensión intrínsecamente histórica del objeto de estudio de la lingüística. Sin embargo, desde el punto de vista de la estructura de la lengua, el signo lingüístico es y sigue siendo inmutable.

De hecho, ninguna sociedad conoce ni jamás ha conocido la lengua de otro modo que como un producto heredado de las generaciones precedentes y que hay que tomar tal cual es. Ésta es la razón de que la cuestión del origen del lenguaje no tenga la importancia que se le atribuye generalmente. Ni siquiera es cuestión que se deba plantear; el único objeto real de la lingüística es la vida normal y regular de una lengua ya constituida. Un estado de lengua dado siempre es el producto de factores históricos, y esos factores son los que explican por qué el signo es inmutable, es decir, por qué resiste toda sustitución arbitraria ${ }^{13}$ (Saussure, 1973: 136).

${ }^{11}$ Se podría objetar, además, que la afirmación de que "las alteraciones son ciertamente externas al sistema, no determinadas por él" debería ser matizada, puesto que es la organización misma del sistema, la trama de las relaciones diferenciales que lo integran, tanto las asociativas como las sintácticas, lo que permite, favorece y aun determina ciertas transformaciones (y a fortiori ciertas conservaciones; véase supra nota 10). Sin embargo, esta objeción tendría valor sólo si se considerara la lengua en su totalidad. En realidad, en el sistema dicotómico de Saussure, queda claro que las alteraciones y transformaciones sólo se pueden dar en las realizaciones concretas de los hablantes, en la parole, y que sólo "son absorbidas" por la langue una vez generalizadas y convertidas en un hecho colectivo.

12 "El signo lingüístico es radicalmente arbitrario, en ambas componentes, significado y significante; por consiguiente, la sola razón que determina la configuración particular de un significante o un significado es el hecho de que así y no diversamente lo delimitan los demás significantes y significados coexistentes con aquel en el mismo sistema. Desde un punto de vista objetivo esto significa que t o d o el valor de un signo depende, a través del sistema, de la sociedad que mantiene con vida en aquel modo concreto el sistema mismo, y, por ende, de las vivencias históricas de la sociedad [...]. De modo que el valor lingüístico es radicalmente histórico (o, si se prefiere un término menos equívoco, contingente). Desde el punto de vista del método de investigación, esto significa que, para estudiar un signo en su realidad de signo, hay que considerarlo en el sistema del que recibe su valor" (De Mauro, 1967b: 424; la traducción es mía).

${ }^{13}$ La arbitrariedad del signo, a saber, el vínculo inmotivado entre significante y significado, "pone a la lengua al abrigo de toda tentativa que pueda modificarla" (Saussure, 1973: 137); en otros términos, la única justificación 
Es decir: el signo lingüístico no cambia, y debe ser estudiado según modalidades específicamente sincrónicas, precisamente porque la langue es un producto histórico. Y es por ello que para Saussure, tal como señalamos en la primera parte de este texto (Lampis, 2018) y repetimos en el punto 5 de nuestra introducción, la lingüística no es una ciencia histórica, sino semiológica. Comenta De Mauro:

Historia e histórico son términos que una larga tradición ha cargado de múltiples sentidos, y resultan por lo tanto equívocos. En lingüística, ha habido y hay, entre otros, un sentido según el cual historia se usa como sinónimo de devenir, de diacronía. Es pensando en esta acepción que Saussure insiste en el carácter "anti-histórico" del sistema lingüístico, y de la lingüística sincrónica que lo describe. Pero historia e histórico también tienen otro sentido: es el sentido según el cual histórico se dice, por ejemplo, de un sistema de leyes jurídicas, en tanto que se asume que este sistema se halla ligado a la contingencia temporal y social. En este sentido, como Saussure bien supo ver, un estado de lengua es histórico no ya porque "se desarrolla", sino porque las motivaciones que lo sostienen son de carácter contingente, temporal y socialmente determinado. Si, como parece el caso, se asume que tan sólo este segundo sentido (que no niega, sino que incluye al primero) es plenamente conforme al pensamiento y al lenguaje del moderno historicismo, nos hallamos en la necesidad de formular una conclusión. Saussure, precisamente al profundizar en el análisis de los aspectos universales de la realidad lingüística, al elaborar su propia versión de la antigua grammaire géneréle, individuó el carácter radicalmente arbitrario y por ende radicalmente social de todas las lenguas: con ello, también sancionó su carácter radicalmente histórico (De Mauro, 1967a: XVIII; la traducción es mía).

Un carácter radicalmente histórico que el analista, sin embargo, deberá convenientemente poner entre paréntesis. Porque la gramática general, cuyo objetivo es el de fundamentar y legitimar el estudio científico de las multiformes realizaciones y actualizaciones de los hablantes, dependerá en todo caso de nuestra capacidad de abstraer un sistema subyacente e invariable de relaciones fundamentales, operación que finalmente, en autores como Hjelmslev y Greimas, conducirá a la priorización del principio de inmanencia y a la definición de cierto tipo de semiótica y de lingüística estructuralistas.

Así pues, si por un lado Saussure afirma que las lenguas permanecen y que a la vez cambian constantemente, así en el tiempo como en el espacio (principios de continuidad y mutabilidad de la lengua), por otro defiende que lo único que nos permite apreciar tal continuidad y mutabilidad es la conciencia del sistema de la lengua. Dicha conciencia es necesariamente sincrónica e inmanente; es decir: aunque dependa causalmente de factores contingentes, sociales e históricos, puede y debe ser estudiada prescindiendo de tales factores. Como escribió el propio Saussure en unas notas preparatorias para un artículo sobre Whitney:

La situación exacta del lenguaje entre las cosas humanas es tal que es extremadamente dudoso y delicado decir si se trata más bien de un objeto histórico o más bien de otra cosa pero en el estado actual de las tendencias no hay ningún peligro en insistir especialmente en su vertiente no histórica.

de la existencia del signo lingüístico es, en primer lugar, socio-histórica y, en segundo lugar, sistémica, de modo que el signo no puede ser cambiado "arbitrariamente" por ningún hablante. 
Que en cada momento de su existencia el lenguaje es un producto histórico, es lo que es evidente. Pero que en ningún momento del lenguaje ese producto histórico represente otra cosa que el último compromiso que acepta la mente con ciertos símbolos, esa es una verdad más absoluta todavía, pues sin este último hecho no habría lenguaje. Por el modo en que la mente puede utilizar un símbolo ${ }^{14}$ (dado, en primer lugar, que el símbolo no cambia) es toda una ciencia que no tiene nada que ver con las condiciones históricas. Además, si el símbolo cambia, se produce inmediatamente después un nuevo estado, que exige una aplicación nueva de las leyes universales (Saussure, 2004: 187).

En otros apuntes dedicados a la morfología histórica, hallamos lo que según Saussure (2004: 172) sería el gran principio que debe guiar la individuación de unidades morfológicas pertinentes (raíces, afijos y desinencias): "lo que es real en un estado dado del lenguaje es aquello de lo que los sujetos hablantes tienen conciencia, todo aquello de lo que tienen conciencia y nada más que aquello de lo que pueden tener conciencia", y esta "realidad" sólo se puede aprehender y reconstruir a partir de un sistema sincrónico —o idiosincrónico— de signos interrelacionados sintagmática y asociativamente; como se especifica en el Curso:

La sincronia no conoce más que una perspectiva, la de los sujetos hablantes, y todo su método consiste en recoger su testimonio; para saber en qué medida una cosa es realidad será necesario y suficiente averiguar en qué medida existe para la conciencia de los sujetos hablantes (Saussure, 1973: 161).

Ahora bien, se puede cuestionar el aserto fundamental de que los hablantes tienen una "consciencia puramente sincrónica" de la lengua que emplean o, en otros términos, que la articulación "real" (y arbitraria, desde luego) entre formas significantes ("imágenes acústicas") y formas significadas ("conceptos") resulta comprensible sólo al ser debidamente interpretada como una estructura (un "panorama") invariante de elementos y relaciones que todos "ven" de una forma parecida; se puede cuestionar, asimismo, la importancia y el alcance real del análisis ("psicolingüístico") saussureano basado en la reconstrucción de campos asociativos y sintagmáticos; y se puede cuestionar, finalmente, el aserto de que toda innovación lingüística depende de la creatividad o las oscilaciones propias de la parole, mientras que todo equilibrio sistémico pertenece a los mecanismos organizadores de la langue. Y aun así se debería reconocer que la distinción metodológica entre sincronía y diacronía, a los cien años de la publicación del Curso, sigue plenamente vigente. Lo que no es vigente es más bien el hiato metodológico fuerte que Saussure llegó a plantear en nombre de unas exigencias de cientificidad que, lisa y llanamente, han venido perdiendo "fuelle" a lo largo del siglo XX, así como lo demuestran nociones explicativas tales como "estructura dinámica" y "concreción histórica", nociones que tienden a anular el hiato requerido entre sistema y proceso, entre estructura e historia, sin por ello abandonar el ámbito de un honesta y rigurosa investigación científica.

14 Aquí la voz "símbolo" se emplea como sinónimo de "signo", otra oscilación terminológica que no encontrará cabida en el Curso. 


\section{REFERENCIAS BIBLIOGRÁFICAS}

Alighieri, D. (2010) [c. 1305]. De vulgari eloquentia (libri duo). Bacheca Ebook.

Alonso, A. (1945). Prólogo a la edición española. En Saussure, 1973: 7-30.

BARThes, R. (1990) [1964]. Elementos de semiología. En La aventura semiológica. R. Barthes, 18-83. Barcelona: Paidós.

Bastardas Boada, A. (2016). "Ecología lingüística y lenguas minorizadas: algunas notas sobre el desarrollo del campo". En 53 reflexiones sobre aspectos de la fonética y otros temas de la lingüística. A. M. Fernández Planes (ed.), 449-458. Barcelona: Universitat de Barcelona.

Benveniste, É. (1997) [1966]. Problemas de lingüística general 1. Madrid: Siglo XXI.

Bouquet, S. (2005). "Après un siècle, les manuscrits de Saussure reviennent bouleverser la linguistique". Texto! Textes \& Cultures junio 2005, http://www.revue-texto.net/Saussure/Sur_Saussure/ Bouquet_Apres.html [11/05/2018].

Chomsky, N. (1991) [1988]. Linguaggio e problema della conoscenza. Bolonia: Il Mulino.

Círculo Lingüístico de Praga (I970) [i929]. Tesis. Madrid: Alberto Corazón.

Coquet, J.-C. (2008). Le istanze enuncianti. Semiotica e fenomenologia. Milán: Mondadori.

Coseriu, E. (1992) [1988]. Competencia lingüística. Elementos de la teoría del hablar. Madrid: Gredos.

De Mauro, T. (1967a). Introduzione. En Saussure, 2005b: V-XXIII.

- (I967B). Notizie biografiche e critiche su F. de Saussure / Note. En Saussure, 2005b: 285-456.

Lampis, M. (2018). "Una lectura semiótica del Cours en el año de su centenario". Signa. Revista de la Asociación Española de Semiótica 27, 687-718.

LePSCHY, G. C. (1979). «Lingua/parola». En Enciclopedia Einaudi. Volume 8, 340-351. Turín: Einaudi.

Monod, J. (2010) [1970]. Il caso e la necessità. Saggio sulla filosofia naturale della biologia contemporanea. Milán: Mondadori.

RASTIER, F. (2005). "Saussure au futur: écrits retrouvés et nouvelles réceptions". Texto! Textes \& Cultures marzo 2005, http://www.revue-texto.net/Saussure/Sur_Saussure/Rastier_Saussure.html [11/05/2018].

Saussure, F. de (1973) [1945]. Curso de lingüística general. Buenos Aires: Losada.

- (2005A) [1916]. Cours de linguistique générale. París: Payot.

- (2005B) [1967]. Corso di linguistica generale. Roma-Bari: Laterza.

- (2004). Escritos de lingüística general. Barcelona: Gedisa. 
